\title{
Robert Lafont, L'être de langage. Pour une anthropologie linguistique
}

\section{Giovanni Agresti}

\section{(2) OpenEdition}

1 Journals

Édition électronique

URL : http://journals.openedition.org/studifrancesi/35402

DOI : 10.4000/studifrancesi.35402

ISSN : 2427-5856

Éditeur

Rosenberg \& Sellier

\section{Édition imprimée}

Date de publication : 1 novembre 2005

Pagination : 466

ISSN : 0039-2944

\section{Référence électronique}

Giovanni Agresti, «Robert Lafont, L'être de langage. Pour une anthropologie linguistique », Studi Francesi

[En ligne], 146 (XLIX | II) | 2005, mis en ligne le 30 novembre 2015, consulté le 18 avril 2021. URL http://journals.openedition.org/studifrancesi/35402; DOI : https://doi.org/10.4000/studifrancesi. 35402

Ce document a été généré automatiquement le 18 avril 2021.

\section{(c) $($ ) $\odot$ (8)}

Studi Francesi è distribuita con Licenza Creative Commons Attribuzione - Non commerciale - Non opere derivate 4.0 Internazionale. 


\title{
Robert Lafont, L'être de langage. Pour une anthropologie linguistique
}

\author{
Giovanni Agresti
}

\section{RÉFÉRENCE}

ROBERT LAFONT, L'être de langage. Pour une anthropologie linguistique, Limoges, Lambert-

Lucas, 2004, pp. 118.

1 Les lecteurs du Robert Lafont linguiste trouveront dans cet ouvrage mince et extrêmement dense - et, malgré ceci, plutôt souple - un outil précieux voire indispensable pour avoir accès à l'approche praxématique, d'autant plus que les ouvrages en ayant jalonné la constitution (à l'exception des trois derniers parus depuis 1997 chez L'Harmattan) sont aujourd'hui presque introuvables [La Phrase occitane (1967), Le Travail et la Langue (1978), Concepts de la praxématique (1989), Le Dire et le Faire (1990), Il y a quelqu'un: la Parole et le Corps (1994)]. Comme l'auteur lui-même le dit dans son «Avant-propos», «Il m'apparaît aujourd'hui que ces résultats d'une réflexion d'une trentaine d'années, distribués en plusieurs ouvrages que je maintiens en référence, [...] méritent cet exposé et une présentation plus «pédagogique» [...]. On trouvera donc ici la praxématique dans son aboutissement actuel, tel que dans la pensée de son initiateur, sous une forme d'exposé allégé et succinct».

2 Le volume est structuré en quatre parties: 1) «Le corps et l'espace», où l'auteur considère le corps humain, son architecture et son inscription spatiale et temporelle (ainsi que les coordonnées et les virtualités langagières et cognitives qui en découlent) comme le point de départ nécessaire de sa réflexion; 2) «La forme signifiante», où l'on établit des connexions (dont ces schèmes indoeuropéens invalidant, du moins en une certaine mesure, le principe de l'arbitraire du signe) entre le corps humain et ses facultés communicatives, notamment la voix; 3) «La signifiance», où l'on passe de la puissance à signifier à l'actualisation de la volonté de signifier, à travers, aussi, une reprise et une critique de la psychomécanique de Guillaume et une nouvelle approche 
de la théorie des actes de parole; 4) «Réalité et sujet», où l'auteur analyse le statut du je, le critère de réalité et la construction de l'identité individuelle pour en arriver à cerner les composantes mises en jeu par la pulsion communicative dans un cadre relationnel et éclaircir un bref historique des déchirements du sujet, dont la «névrose diglossique» et «l'aliénation du travail vivant» jouent sans doute le rôle principal. 